\title{
Dose patterns in commercially insured subjects chronically exposed to opioids: a large cohort study in the United States
}

\author{
Maria Soledad Cepeda*1, Mila Etropolski¹, Rachel Weinstein¹, Daniel Fife'1, Raymond Boston² and Amy Matcho
}

\begin{abstract}
Background: Little data exist on how opioid doses vary with the length of exposure among chronic opioid users.

Methods: To characterize the change in the dosage of opioids over time, a retrospective cohort study using the PharMetrics database for the years 1999 through 2008 was conducted. Individuals exposed to opioids in 2000 who had 2 opioid dispensings at least 6 months apart and were opioid naive (did not receive any opioid 6 month before their exposure in 2000) were included. The date of the first dispensing in 2000 was defined as the index date and the dispensing had to be for a strong and full agonist opioid. All opioid doses were converted to oral morphine equivalent doses. Exposure was classified as continuous or intermittent. Mean, median, interquartile range, and $95^{\text {th }}$ percentile of opioid dose over 6-month periods, as well as the percentage of subjects who ever received a high or very high opioid dose, were calculated.

Results: Among the 48,986 subjects, the mean age was 44.5 years and $54.5 \%$ were women. Intermittent exposure was observed in $99 \%$ of subjects; continuous exposure was observed in $1 \%$ of subjects. The mean duration of exposure for the subjects who were continuously exposed to opioids was 477 days. In subjects with no cancer diagnosis who were continuously exposed to opioids, the mean, $25^{\text {th }}, 50^{\text {th }}$, and $75^{\text {th }}$ percentile of dose was stable during the first 2 years of use, but the $95^{\text {th }}$ percentile increased. Seven percent of them were exposed to doses of $180 \mathrm{mg}$ or more of morphine at some point.

Conclusions: Dose escalation is uncommon in subjects with intermittent exposure to opioids. For subjects with continuous exposure to opioids who have cancer, doses rise substantially with time. For those without cancer, doses remain relatively stable for the first 2 years of use, but subsequently increase. Seven percent of subjects with no cancer diagnosis will be exposed to daily doses of $180 \mathrm{mg}$ or more of morphine equivalent at some point.
\end{abstract}

\section{Background}

Opioids are increasingly used for the treatment of chronic malignant and nonmalignant pain $[1,2]$ and systematic reviews of randomized controlled trials have confirmed their short-term efficacy for the treatment of neuropathic pain, back pain, ostearthritis, cancer pain, and fibromyalgia [3-8].

However, in some cases with chronic use, the dose of opioids may increase because of disease progression, the development of tolerance and/or the development of a state of abnormal high pain sensitivity (hypersensitivity)

* Correspondence: scepeda@its.jnj.com

1 Johnson \& Johnson Pharmaceutical Research and Development, Titusville, NJ, USA

Full list of author information is available at the end of the article that opioids themselves may induce. Hypersensitivity is a poorly understood phenomenon thought to result from opioid-induced neuroplastic changes in the peripheral and central nervous systems that lead to sensitization of pronociceptive pathways $[1,9]$.

Little data exist to support the long-term efficacy of opioids or to describe the relation between opioid dose and the length of exposure among chronic opioid users [10]. Although randomized controlled trials have evaluated opioids for the treatment of chronic pain, most of these trials have limited follow-up periods (around 16 weeks) [3-5] and in the trials with longer follow-up periods, the lack of generalizability of the findings has been identified as a serious shortcoming [4]. 
Claims databases provide an opportunity to close this gap in knowledge. These databases are a collection of health insurance claims that are maintained largely for billing and administrative purposes. Nevertheless, they permit the evaluation of not only a diverse population, but also a large number of subjects followed over a relatively long period of time in a real-world setting [11].

Health care databases have been used extensively for pharmacoepidemiologic research in many therapeutic areas including pain [12-14] to describe health care utilization, patterns of care, disease prevalence, drug and disease outcomes, and cost of care. There are, however, limitations to the use of health care databases for pharmacoepidemiologic research: they are observational, which limits inferences about treatment efficacy relative to studies that include random allocation to treatment [11]; they may not include information on important confounding factors (eg, smoking), and they may include diagnoses that are provisional or whose selection may be affected by reimbursement policies. The advantages to the use of these databases are the availability of systematic and accurate information on prescribed medications [11], their ability to follow patients for many years, and the fact that they reflect clinical practice in a population that is not subject to the same selection biases as might apply to those who volunteered for inclusion in a study. In fact, health care databases often are used to explain differences in findings between trial data and clinical practice [15].

We sought to characterize the dose of opioids in both cancer and noncancer patients intermittently and chronically exposed to opioids using PharMetrics Patient-Centric database. PharMetrics is the largest health care claims database in the United States and is representative of the commercially insured population. Data for more than 61 million individuals from more than 98 health plans across the United States are available and include information on all hospitalizations, emergency care, office visits, and drug dispensing covered by insurance.

\section{Methods}

To characterize the change in the dose of opioids over time, a retrospective cohort study using the PharMetrics Patient-Centric database for the years 1999 through 2008 was conducted. Access to the PharMetrics database requires a license agreement and the data are provided de-identified. Tabulations from these data do not require ethics approval.

\section{Inclusion and exclusion criteria}

Opioid-naive individuals exposed to opioids in 2000 who had 2 strong opioid dispensings at least 6 months apart (to focus on subjects with long-term opioid exposure), regardless of the duration of the prescription, were included. Opioid-naive individuals were defined as subjects who did not receive any type of opioid for at least 6 months before their first opioid dispensing in 2000 .

The date of the first dispensing of a strong opioid prescription in 2000 was defined as the index date. The dispensing at the index date had to be for a strong and full agonist opioid (e.g., morphine, hydromorphone), Table 1. Oral, rectal, transdermal, subcutaneous, intramuscular or intravenous routes of administration and all forms of presentation (immediate release or controlled release) were included. A subject remained in the cohort even if after receiving a strong opioid at the index date, he or she subsequently received a weak, agonist antagonist, or partial agonist opioid. All opioid doses were converted into oral morphine equivalent doses.

Patients who were receiving opioids for the treatment of opioid addiction were excluded. To determine presence of addiction before the index date, the International Statistical Classification of Diseases and Related Health Problems, ninth edition (ICD-9) diagnostic codes for drug dependence or drug abuse were used.

\section{Pattern of exposure}

Exposure was classified as either continuous or intermittent. A subject was defined as "continuously exposed" if there were no time gaps between the dispensing of opioids, and "intermittently exposed" if there was a time gap between the dispensing of opioids. A gap was considered to occur when the number of days between 2 dispensings was more than 4 times the number of days supplied by the previous dispensing. Four times the days supplied was

Table 1: Strong opioids dispensed at index date

\begin{tabular}{ll}
\hline Opioid medication & Percentage \\
\hline Fentanyl & 0.2 \\
\hline Hydrocodone & 78.8 \\
\hline Hydromorphone & 0.2 \\
\hline Meperidine & 1.7 \\
\hline Methadone & 0.004 \\
\hline Morphine & 0.2 \\
\hline Oxycodone & 18.7 \\
\hline Oxymorphone & 0.002 \\
\hline
\end{tabular}

*Percentages may not add up to $100 \%$ because of rounding. 
used to take into account that some patients may have taken the medication less often than prescribed.

\section{Daily dose and dose over time}

Daily dose was calculated from the quantity dispensed and the days supplied. Daily doses were re-expressed as oral morphine equivalents using the conversion factors shown in Table 2.

To determine the behavior of opioid dose over time, mean, median dosage, interquartile range and $95^{\text {th }}$ percentile of opioid dose over 6-month periods from the index date were calculated. Opioid doses are reported separately for subjects with intermittent or continuous

Table 2: Morphine equivalent conversion factors

\begin{tabular}{|c|c|}
\hline Opioid drug & Oral morphine equivalent dose \\
\hline Buprenorphine & Multiplied by 60 \\
\hline Butorphanol & Multiplied by 7 \\
\hline Codeine & Divided by 12 \\
\hline Dihydrocodeine & Divided by 10 \\
\hline Fentanyl (patch) & Multiplied by 150 \\
\hline Hydrocodone & Multiplied by 1.5 \\
\hline Hydromorphone (oral) & Multiplied by 5 \\
\hline $\begin{array}{l}\text { Hydromorphone } \\
\text { (parenteral) }\end{array}$ & Multiplied by 10 \\
\hline Levorphanol & Multiplied by 6 \\
\hline Meperidine & Divided by 12 \\
\hline Methadone & Multiplied by 10 \\
\hline Morphine (parenteral) & Multiplied by 2 \\
\hline Oxycodone & Multiplied by 1.5 \\
\hline Oxymorphone & Multiplied by 10 \\
\hline Pentazocine & Divided by 4 \\
\hline Propoxyphene & Divided by 24 \\
\hline Tramadol & Divided by 5 \\
\hline
\end{tabular}

exposures and, for subjects with continuous exposure, by the presence or absence of a cancer diagnosis.

To address the possibility that aggregate dose changes at the cohort level might be affected by selective loss of the subjects with the highest or lowest doses, in each 6month period, the dose of opioids for subjects who remained in the cohort during all or part of the next 6month period were examined separately from subjects who, for any reason, did not continue to the next 6month period.

The database does not explicitly link medication dispensings to their indications. To assess the likely indications for the opioids that were dispensed, ICD-9 painrelated diagnostic codes were grouped into cancer, musculoskeletal, migraine, neuropathic, and other. Because many opioid dispensings did not have an ICD-9 painrelated diagnosis that was close in time, no time limitation was placed on these pain diagnoses.

The percentage of subjects who ever received a high or very high opioid dose was also calculated. Morphine equivalents of $180 \mathrm{mg} /$ day or more were considered as the high dose category, and morphine equivalents of 300 $\mathrm{mg} /$ day or more were considered as the very high dose category $[1,16]$. In addition, the percentage of subjects who ever received morphine equivalents of $100 \mathrm{mg} /$ day or more was also calculated as such doses have been associated with an increase risk of overdose [17].

The analyses were performed in STATA IC version 10.1 .

\section{Results}

A total of 57,345 subjects were exposed to opioids starting in 2000 for at least 6 months and met the inclusion criteria. Of these, 8,362 (14\%) subjects were excluded because of missing data on the quantity dispensed or the days supplied, leaving 48,986 subjects whose dosage patterns were examined in the present study. Among these subjects, the mean age was 44.5 years and $54.5 \%$ were women. Subjects were diagnosed with various possible types of pain (some subjects were diagnosed with more than one type), including musculoskeletal, $77.6 \%$; neuropathic, 35.3\%; migraine, $27.8 \%$; and cancer, $24.2 \%$.

At the index date, the most frequently dispensed opioid was hydrocodone $(78.8 \%$ of subjects), followed by oxycodone $(18.7 \%$ of subjects) and meperidine $(1.7 \%$ of subjects). Fentanyl, hydromorphone, methadone, morphine, and oxymorphone together accounted for the remaining $0.8 \%$ of dispensing at the index date (Table 1 ).

\section{Pattern of exposure: Intermittent and continuous}

Intermittent exposure was observed among 48,367 (99\%) of subjects; continuous exposure was observed among $619(1 \%)$ of subjects. The median number of opioid dispensings was 5 for subjects with intermittent exposure 
Table 3: Morphine equivalent daily dose by time in subjects with intermittent exposure

\begin{tabular}{|c|c|c|c|c|c|c|c|c|}
\hline Years & Number of subjects & Mean \pm SD & Median & Min & Max & P25 & P75 & P95 \\
\hline Half year & 48367 & $62.48 \pm 76.43$ & 50.00 & 0.25 & 2700.00 & 37.50 & 69.17 & 112.50 \\
\hline$>6$ months to 1 year & 22494 & $57.61 \pm 85.68$ & 45.00 & 0.33 & 6666.67 & 31.50 & 65.16 & 112.50 \\
\hline$>1$ to 1.5 years & 19130 & $56.07 \pm 69.1$ & 45.00 & 0.50 & 2250.00 & 30.00 & 64.11 & 112.50 \\
\hline$>1.5$ to 2 years & 15553 & $56.97 \pm 73.8$ & 45.00 & 0.50 & 2025.00 & 30.00 & 65.00 & 112.50 \\
\hline$>2$ to 2.5 years & 11588 & $58.45 \pm 69.05$ & 46.15 & 0.67 & 1920.00 & 30.00 & 67.50 & 113.44 \\
\hline$>2.5$ to 3 years & 8119 & $60.73 \pm 82.99$ & 46.88 & 0.67 & 1920.00 & 30.94 & 67.50 & 120.00 \\
\hline$>3$ to 3.5 years & 5824 & $58.23 \pm 81.27$ & 45.00 & 1.56 & 2660.63 & 30.00 & 64.29 & 112.50 \\
\hline$>3.5$ to 4 years & 4677 & $55.71 \pm 75.7$ & 45.00 & 2.50 & 1808.04 & 30.00 & 60.00 & 112.50 \\
\hline$>4$ to 4.5 years & 4619 & $58.57 \pm 87.44$ & 45.00 & 2.50 & 2025.00 & 30.00 & 60.00 & 120.00 \\
\hline$>4.5$ to 5 years & 4111 & $59.42 \pm 100.09$ & 45.00 & 2.50 & 2700.00 & 30.00 & 60.00 & 112.50 \\
\hline$>5$ to 5.5 years & 3418 & $58.56 \pm 96.34$ & 45.00 & 2.50 & 3535.12 & 30.00 & 60.00 & 120.00 \\
\hline$>5.5$ to 6 years & 3301 & $62.96 \pm 113.2$ & 45.00 & 2.50 & 2890.19 & 30.00 & 61.25 & 120.00 \\
\hline$>6$ to 6.5 years & 3225 & $61.66 \pm 109.87$ & 45.00 & 2.45 & 3368.28 & 30.00 & 62.00 & 120.00 \\
\hline$>6.5$ to 7 years & 3031 & $61.81 \pm 101.48$ & 45.00 & 2.50 & 2239.86 & 30.00 & 60.99 & 114.28 \\
\hline$>7$ to 7.5 years & 1837 & $64.44 \pm 116.78$ & 45.00 & 3.75 & 2695.92 & 30.00 & 60.00 & 128.57 \\
\hline$>7.5$ to 8 years & 714 & $62.71 \pm 103.76$ & 45.00 & 4.17 & 1350.00 & 30.00 & 56.25 & 146.93 \\
\hline$>8$ years & 179 & $72.52 \pm 124.42$ & 46.32 & 6.94 & 937.50 & 28.75 & 60.00 & 300.00 \\
\hline
\end{tabular}

SD, standard deviation; $P 25,25^{\text {th }}$ percentile; $P 75 ; 75^{\text {th }}$ percentile; $P 95 ; 95^{\text {th }}$ percentile

(range, 2-319 dispensings) and 13 for subjects with continuous exposure (range, 2-275 dispensings). The mean duration of exposure in the subjects continuously exposed to opioids was 477 days (range, 6 months to 8 years).

The median daily dose of morphine equivalent in the subjects with intermittent exposure remained stable over time, at approximately the equivalent of $50 \mathrm{mg}$ oral morphine per day. The mean (approximately $60 \mathrm{mg}$ ), twentyfifth percentile (approximately $30 \mathrm{mg}$ ), seventy-fifth percentile (approximately $60 \mathrm{mg}$ ) and ninety-fifth percentile (approximately $120 \mathrm{mg}$ ) doses were also stable over time (Table 3).
Six hundred and nineteen subjects were continuously exposed to opioids for at least 6 months, and 6 years after the index day, only 9 subjects were continuously exposed to opioids. The daily morphine equivalent dose in subjects with continuous exposure and no cancer diagnosis remained stable for the first two years, as measured by mean (approximately $70 \mathrm{mg}$ ), median (approximately 50 $\mathrm{mg}$ ), twenty-fifth (approximately $30 \mathrm{mg}$ ) or seventy-fifth percentiles (approximately $75 \mathrm{mg}$ ), but the $95^{\text {th }}$ percentile dose rose from $143 \mathrm{mg}$ to $185 \mathrm{mg}$. After the second year of continuous exposure, although the median dose remained stable, the mean, seventy-fifth percentile and 
Table 4: Morphine equivalent daily dose by time in subjects with continuous exposure without cancer diagnosis

\begin{tabular}{|c|c|c|c|c|c|c|c|c|}
\hline Years & Number of subjects & Mean \pm SD & Median & Min & Max & P25 & P75 & P95 \\
\hline Half year & 442 & $62.53 \pm 69.88$ & 45.04 & 7.5 & 802.13 & 30.54 & 67.5 & 142.5 \\
\hline$>6$ months to 1 year & 305 & $62.11 \pm 65.73$ & 45 & 7.5 & 486.86 & 30 & 64.29 & 170 \\
\hline$>1$ to 1.5 years & 173 & $66.37 \pm 64.39$ & 46.61 & 7.5 & 480 & 30 & 73.5 & 197.14 \\
\hline$>1.5$ to 2 years & 107 & $64.6 \pm 62.1$ & 45.8 & 7.5 & 342.86 & 30 & 64.29 & 184.85 \\
\hline$>2$ to 2.5 years & 67 & $71.96 \pm 70.86$ & 50.63 & 8.33 & 360 & 30 & 82.12 & 183.33 \\
\hline$>2.5$ to 3 years & 29 & $88.2 \pm 91.12$ & 60 & 8.33 & 420 & 39.99 & 95.45 & 330 \\
\hline$>3$ to 3.5 years & 19 & $91.05 \pm 115.16$ & 53.09 & 8.33 & 480 & 30 & 90.91 & 480 \\
\hline$>3.5$ to 4 years & 14 & $68.13 \pm 53.39$ & 52.5 & 15 & 187.5 & 24.64 & 107.76 & 187.5 \\
\hline$>4$ to 4.5 years & 12 & $90.38 \pm 79.83$ & 52.5 & 15 & 244.55 & 30 & 169 & 244.55 \\
\hline$>4.5$ to 5 years & 9 & $80.99 \pm 61.23$ & 60 & 22.5 & 183 & 45 & 95.98 & 183 \\
\hline$>5$ to 5.5 years & 6 & $111.56 \pm 72.04$ & 117.18 & 22.5 & 187.5 & 45 & 180 & 187.5 \\
\hline$>5.5$ to 6 years & 6 & $122.59 \pm 89.37$ & 120.27 & 22.5 & 240 & 45 & 187.5 & 240 \\
\hline$>6$ to 6.5 years & 5 & $122.88 \pm 105.75$ & 75 & 22.5 & 255 & 45 & 216.92 & 255 \\
\hline$>6.5$ to 7 years & 5 & $133.5 \pm 132.31$ & 60 & 22.5 & 330 & 45 & 210 & 330 \\
\hline$>7$ to 7.5 years & 2 & $123.41 \pm 110.89$ & 123.41 & 45 & 201.82 & 45 & 201.82 & 201.82 \\
\hline$>7.5$ to 8 years & 2 & $127.5 \pm 116.67$ & 127.5 & 45 & 210 & 45 & 210 & 210 \\
\hline$>8$ years & 1 & $45 \pm$ & 45 & 45 & 45 & 45 & 45 & 45 \\
\hline
\end{tabular}

SD, standard deviation; $P 25,25^{\text {th }}$ percentile; $P 75 ; 75^{\text {th }}$ percentile; $P 95 ; 95^{\text {th }}$ percentile

ninety-fifth percentile doses rose gradually. After the fourth year of continuous exposure the median opioid dose increased as well, though it should be noted that the number of subjects was small. The daily morphine equivalent dose in subjects with continuous exposure and a cancer diagnosis increased earlier than in subjects without cancer diagnosis (Tables 4 and 5).

The opioid dose among subjects whose exposure ended in a given 6-month time period was similar to the opioid dose among subjects who remained exposed in the next 6-month time period (Table 6).

\section{Exposure to high doses of opioids}

In subjects who were intermittently exposed to opioids exposure to high doses (180 mg or more of oral morphine equivalent) occurred at some point in 2,095 (4\%) subjects and $1,257(2.6 \%)$ were exposed to very high doses (300 mg or more of oral morphine equivalent).

In subjects who were continuously exposed to opioids, $7.6 \%$ were exposed to high doses of opioids and $2.9 \%$ were exposed to very high doses of opioids at some point. Ten percent of subjects who were continuously exposed to opioids with a cancer diagnosis were exposed to high doses of opioids compared with $7 \%$ of subjects who were 
Table 5: Morphine equivalent daily dose by time in subjects with continuous exposure with cancer diagnosis

\begin{tabular}{|c|c|c|c|c|c|c|c|c|}
\hline Years & Number of subjects & Mean \pm SD & Median & Min & Max & P25 & P75 & P95 \\
\hline Half year & 177 & $65.29 \pm 67.61$ & 50.00 & 7.50 & 699.57 & 33.88 & 77.73 & 140.63 \\
\hline$>6$ months to 1 year & 148 & $86.63 \pm 156.56$ & 55.44 & 7.50 & 1702.50 & 30.00 & 89.10 & 240.00 \\
\hline$>1$ to 1.5 years & 79 & $71.96 \pm 86.73$ & 51.46 & 10.56 & 560.00 & 26.25 & 79.29 & 294.49 \\
\hline$>1.5$ to 2 years & 39 & $90.96 \pm 92.61$ & 60.00 & 15.00 & 431.88 & 30.00 & 98.12 & 347.94 \\
\hline$>2$ to 2.5 years & 19 & $99.55 \pm 87.31$ & 75.00 & 15.00 & 300.00 & 37.50 & 120.00 & 300.00 \\
\hline$>2.5$ to 3 years & 9 & $116.79 \pm 95.72$ & 105.00 & 15.00 & 318.12 & 45.00 & 139.74 & 318.12 \\
\hline$>3$ to 3.5 years & 5 & $121.9 \pm 130.19$ & 45.00 & 15.00 & 298.74 & 27.50 & 223.27 & 298.74 \\
\hline$>3.5$ to 4 years & 5 & $115.78 \pm 125.49$ & 45.00 & 15.00 & 295.71 & 23.82 & 199.38 & 295.71 \\
\hline$>4$ to 4.5 years & 5 & $151.37 \pm 182.88$ & 45.00 & 15.00 & 436.67 & 26.25 & 233.96 & 436.67 \\
\hline$>4.5$ to 5 years & 4 & $304.47 \pm 422.07$ & 141.43 & 15.00 & 920.00 & 30.00 & 578.93 & 920.00 \\
\hline$>5$ to 5.5 years & 3 & $394.28 \pm 457.61$ & 240.00 & 33.75 & 909.09 & 33.75 & 909.09 & 909.09 \\
\hline$>5.5$ to 6 years & 3 & $400.01 \pm 471.87$ & 233.78 & 33.75 & 932.50 & 33.75 & 932.50 & 932.50 \\
\hline$>6$ to 6.5 years & 3 & $315.39 \pm 321.23$ & 240.00 & 38.57 & 667.61 & 38.57 & 667.61 & 667.61 \\
\hline$>6.5$ to 7 years & 2 & $187.59 \pm 209.35$ & 187.59 & 39.55 & 335.62 & 39.55 & 335.62 & 335.62 \\
\hline$>7$ to 7.5 years & 1 & $381.73 \pm$ & 381.73 & 381.73 & 381.73 & 381.73 & 381.73 & 381.73 \\
\hline$>7.5$ to 8 years & 0 & - & - & - & - & - & - & - \\
\hline$>8$ years & 0 & - & - & - & - & - & - & - \\
\hline
\end{tabular}

$\mathrm{SD}$, standard deviation; $\mathrm{P} 25,25^{\text {th }}$ percentile; $\mathrm{P} 75 ; 75^{\text {th }}$ percentile; $\mathrm{P} 95 ; 95^{\text {th }}$ percentile

continuously exposed to opioids without a cancer diagnosis.

In subjects intermittently exposed to opioids, $18.7 \%$ reached doses of $100 \mathrm{mg}$ or more of oral morphine equivalent. In subjects continuously exposed to opioids, $19.9 \%$ reached doses of $100 \mathrm{mg}$ or more of oral morphine equivalent.

\section{Discussion}

The present study reports the patterns of opioid use in a large diverse population across the United States over a substantial time period. Such data are difficult to obtain in traditional clinical studies, but are readily available in pharmacoepidemiologic database studies.
The study showed that intermittent exposure to opioids is a common phenomenon, a finding that has been described previously [18], and that in subjects with intermittent exposure, the dose of opioids remains stable over time. This group potentially includes subjects with subacute pain, pain exacerbations and chronic pain.

The initial median daily oral morphine equivalent dose was approximately $50 \mathrm{mg}$. Such doses aligned with those reported in studies performed in chronic pain clinics [19] and in the general population [18]. In the latter study, Von Korff et al described opioid use in noncancer patients in 2 US health plans.

In subjects with no cancer diagnosis and continuous exposure to opioids, the $95^{\text {th }}$ percentile dose rose early, 
Table 6: Morphine equivalent median daily doses in subjects continuously exposed to opioids by time and by permanence in the cohort

\begin{tabular}{|c|c|c|c|c|}
\hline Time period & $\begin{array}{l}\text { Number of subjects } \\
\text { who did not continue }\end{array}$ & $\begin{array}{l}\text { Median dose in } \\
\text { subjects who did not } \\
\text { continue }\end{array}$ & $\begin{array}{l}\text { Number of subjects } \\
\text { who continued } \\
\text { exposure }\end{array}$ & $\begin{array}{l}\text { Median dose in } \\
\text { subjects who } \\
\text { continued exposure }\end{array}$ \\
\hline Half year & 166 & 56.25 & 453 & 45.0 \\
\hline$>6$ months to 1 year & 200 & 48.21 & 253 & 44.4 \\
\hline$>1$ to 1.5 years & 107 & 51.45 & 145 & 45.0 \\
\hline$>1.5$ to 2 years & 60 & 46.07 & 86 & 49.75 \\
\hline$>2$ to 2.5 years & 48 & 45.67 & 38 & 60.0 \\
\hline$>2.5$ to 3 years & 14 & 75.5 & 24 & 54.06 \\
\hline$>3$ to 3.5 years & 5 & 60 & 19 & 52.2 \\
\hline$>3.5$ to 4 years & 2 & 47.14 & 17 & 45.0 \\
\hline$>4$ to 4.5 years & 4 & 30.52 & 13 & 60.0 \\
\hline$>4.5$ to 5 years & 4 & 37.5 & 9 & 96.0 \\
\hline$>5$ to 5.5 years & 0 & -- & 9 & 156.4 \\
\hline$>5.5$ to 6 years & 1 & 240.0 & 8 & 120.0 \\
\hline$>6$ to 6.5 years & 1 & 240.0 & 7 & 75.0 \\
\hline$>6.5$ to 7 years & 4 & 49.8 & 3 & 210.0 \\
\hline$>7$ to 7.5 years & 1 & 381.7 & 2 & 123.4 \\
\hline$>7.5$ to 8 years & 1 & 210.0 & 1 & 45.0 \\
\hline Median dose & & 56.25 & & 45.0 \\
\hline
\end{tabular}

but the mean, $25^{\text {th }}, 50^{\text {th }}$, and $75^{\text {th }}$ percentile doses remained stable for the first 2 years of use then increased. However, over the full eight year course of the study the median dose of $45 \mathrm{mg}$ increased to $130 \mathrm{mg}$ and the $95^{\text {th }}$ percentile dose increased from $142 \mathrm{mg}$ to $210 \mathrm{mg}$. Seven percent of subjects with no cancer diagnosis received at some point in time high doses of opioids.

The results of the present study are similar to the study by Bercovitch et al in patients receiving palliative care for terminal illnesses. These authors found that only a small percentage of subjects (approximately 9\%) required doses of morphine equivalent to $300 \mathrm{mg}$ or more [16]. The study by Sullivan et al, although not directly assessing the variation of opioid dose over time, corroborates our findings [2]. In that study, opioid use was characterized in commercially insured and publicly insured populations over a 6-year period. The study found that the cumulative yearly opioid dose increase was due to increases in the number of days supplied rather than the dose per day supplied [2]. 
The very large number of subjects exposed to opioids intermittently permits us to characterize with confidence the dose of opioids over time. On the other hand, only a small number of subjects were continuously exposed to opioids for more than 4 years. Therefore, extrapolating the findings of the study beyond this time period is not recommended.

Dose escalation is considered one of the major factors that could curtail the effectiveness of opioids $[1,10]$. The findings of this study show that dose escalation among commercially insured patients who are prescribed opioids continuously occurred in seven percent of subjects. For most subjects with continuous exposure, dose escalation was seen only after the first 2 years of use. A study in a different population, subjects with back injuries at risk for long term disability continuously exposed to opioids for a year, found a more rapid dose escalation --thirty nine percent of subjects moved to a higher dose category at the last quarter of follow up [20].

Exposure to opioids could lead to serious adverse events. A recent study that assessed the risk of overdose in subjects who had continuously received opioids for chronic non-cancer pain for at least three months found overdoses among $0.5 \%$ of subjects ( 1.5 events $/ 1,000$ person years of follow-up), and observed that subjects receiving $100 \mathrm{mg}$ or more of morphine had a nine-fold increase in overdose risk [17]. In the present study approximately twenty percent of the subjects received such doses, at some time during treatment. Patients receiving these doses need close supervision. Future research should attempt to better define the patient groups in which prescription of opioids for non-cancer pain is safe, and those in which it is not.

Among the limitations of the present study, are: the PharMetrics Patient-Centric database reflects the commercially insured population and, therefore, overrepresents the healthy population which is able to work and underrepresents individuals 65 years or older and disabled and low income populations which are insured through Medicare or Medicaid programs. These limitations could affect the generalizability of the study findings. Attrition of subjects because of loss of health insurance may also affect a study like the present one, that is based on claims data, but some reassurance about this possible source of bias is provided by the finding doses in the preceding six months were similar for subjects who left the cohort and those who remained in it. In addition, the claims database reflects only those dispensings that were submitted for reimbursement in the outpatient setting. It is not able to identify medications that a patient may have obtained outside the health care benefit system. However, the PharMetrics Patient-Centric database captures data from all retail and mail-order dispens- ing regardless of which health care provider in the plan issues the prescription.

Pain intensity or pain relief information is absent in claims databases. Therefore, it is unknown whether subjects stopped treatment with opioids because of disease improvement, the lack of efficacy, or the lack of tolerability. Systematic reviews have found that up to one third of patients in clinical trials withdraw because of opioid adverse events and up to $18 \%$ of patients withdraw because of inadequate pain relief $[3,5]$.

The inability to link with certainty the opioid dispensings directly to the diagnoses that they were intended to address, and the fact that PharMetrics uses the ICD-9 system to code the medical diagnosis, precluded the use of a pain taxonomy based on the pain mechanism. Thus, no attempts were made to compare opioid dose across pain categories, with the exception of the presence of cancer diagnosis.

The pattern of dose escalation observed in this study could be a reflection of the success of the adequate patient selection and careful evaluation by health care providers when prescribing opioids. Consequently, physicians and other health care providers should continue following the principles of good medical practice, and develop treatment plans tailored to the individual and the presenting problem when prescribing opioids, as recommended by many pain organizations such as the American Academy of Pain Medicine and the American Pain Society [21].

\section{Conclusions}

Dose escalation is uncommon in subjects with intermittent exposure to opioids.

For subjects with continuous exposure to opioids who have cancer, doses rise substantially with time. For those without cancer, doses remain relatively stable for the first 2 years of use, but subsequently increase. Seven percent of subjects with no cancer diagnosis will be exposed to daily doses of $180 \mathrm{mg}$ or more of morphine equivalent at some point

\section{Competing interests}

M. Soledad Cepeda, Mila Etropolski, Rachel Weinstein, Daniel Fife, and Amy Matcho are employees of Johnson \& Johnson Pharmaceutical Research \& Development. Johnson \& Johnson Pharmaceutical Research \& Development is an affiliate of Ortho-McNeil-Janssen Pharmaceuticals, Inc, which markets several analgesic drug products including opioids and over-the-counter analgesics such as acetaminophen.

\section{Authors' contributions}

MSC: conceived of the study, participated in its design, execution, and interpretation of data, and drafted the manuscript. ME: participated in the design of the study, interpreted the data, and critically revised the manuscript. RW: participated in the design and execution of the study and critically revised the manuscript. DF: participated in the design of the study, interpreted the data, and critically revised the manuscript. RB: performed the statistical analysis, interpreted the data, and critically revised the manuscript. AM: performed the programming to create the analytic data set, participated in the interpretation 
of the data and critically revised the manuscript. All authors read and approved the final manuscript.

\section{Acknowledgements}

None

\section{Author Details}

IJohnson \& Johnson Pharmaceutical Research and Development, Titusville, NJ, USA and 2 University of Pennsylvania. School of Veterinary Medicine,

Department of Clinical Studies, NBC, Philadelphia, PA, USA

Received: 4 September 2009 Accepted: 18 June 2010

Published: 18 June 2010

\section{References}

1. Ballantyne JC, Mao J: Opioid therapy for chronic pain. NEng/ J Med 2003, 349:1943-1953.

2. Sullivan MD, Edlund MJ, Fan MY, Devries A, Brennan BJ, Martin BC: Trends in use of opioids for non-cancer pain conditions 2000-2005 in Commercial and Medicaid insurance plans: the TROUP study. Pain 2008, 138:440-449.

3. Furlan AD, Sandoval JA, Mailis-Gagnon A, Tunks E: Opioids for chronic noncancer pain: a meta-analysis of effectiveness and side effects. CMAJ 2006, 174:1589-1594.

4. Deshpande A, Furlan A, Mailis-Gagnon A, Atlas S, Turk D: Opioids for chronic low-back pain. Cochrane Database Syst Rev 2007:CD004959.

5. Noble M, Tregear SJ, Treadwell JR, Schoelles K: Long-term opioid therapy for chronic noncancer pain: a systematic review and meta-analysis of efficacy and safety. J Pain Symptom Manage 2008, 35:214-228.

6. Cepeda MS, Camargo F, Zea C, Valencia L: Tramadol for osteoarthritis: a systematic review and metaanalysis. J Rheumatol 2007, 34:543-555.

7. Eisenberg E, MCNicol E, Carr DB: Opioids for neuropathic pain. Cochrane Database Syst Rev 2006, 3:CD006146.

8. Martell BA, O'Connor PG, Kerns RD, Becker WC, Morales KH, Kosten TR, Fiellin DA: Systematic review: opioid treatment for chronic back pain: prevalence, efficacy, and association with addiction. Ann Intern Med 2007, 146:116-127.

9. Chu LF, Angst MS, Clark D: Opioid-induced hyperalgesia in humans: molecular mechanisms and clinical considerations. Clin J Pain 2008, 24:479-496.

10. Cepeda MS: Should opioids be prescribed to treat patients with osteoarthritis? Nat Clin Pract Rheumatol 2008, 4:180-181.

11. Suissa S, Garbe E: Primer: administrative health databases in observational studies of drug effects--advantages and disadvantages. Nat Clin Pract Rheumatol 2007, 3:725-732.

12. Jordan KP, Croft P: Opportunities and limitations of general practice databases in pain research. Pain 2008, 137:469-470.

13. Berger A, Hoffman DL, Goodman S, Delea TE, Seifeldin R, Oster G: Therapy switching in patients receiving long-acting opioids. Ann Pharmacother 2004, 38:389-395.

14. Hall GC, Carroll D, Parry D, McQuay HJ: Epidemiology and treatment of neuropathic pain: the UK primary care perspective. Pain 2006, 122:156-162.

15. Arellano FM, Yood MU, Wentworth CE, Oliveria SA, Rivero E, Verma A, Rothman KJ: Use of cyclo-oxygenase 2 inhibitors (COX-2) and prescription non-steroidal anti-inflammatory drugs (NSAIDS) in UK and USA populations. Implications for COX-2 cardiovascular profile. Pharmacoepidemiol Drug Saf 2006, 15:861-872.

16. Bercovitch $M$, Adunsky A: Patterns of high-dose morphine use in a home-care hospice service: should we be afraid of it? Cancer 2004, 101:1473-1477.

17. Dunn KM, Saunders KW, Rutter CM, Banta-Green CJ, Merrill JO, Sullivan MD, Weisner CM, Silverberg MJ, Campbell CI, Psaty BM, Von KM: Opioid prescriptions for chronic pain and overdose: a cohort study. Ann Intern Med 2010, 152:85-92.

18. Korff MV, Saunders K, Thomas RG, Boudreau D, Campbell C, Merrill J, Sullivan MD, Rutter CM, Silverberg MJ, Banta-Green C, Weisner C: De facto long-term opioid therapy for noncancer pain. Clin J Pain 2008 24:521-527.

19. Buntin-Mushock C, Phillip L, Moriyama K, Palmer PP: Age-dependent opioid escalation in chronic pain patients. Anesth Analg 2005, 100:1740-1745
20. Franklin GM, Rahman EA, Turner JA, Daniell WE, Fulton-Kehoe D: Opioid use for chronic low back pain: A prospective, population-based study among injured workers in Washington state, 2002-2005. Clin J Pain 2009, 25:743-751.

21. A consensus statement from American Academy of Pain Medicine and American Pain Society. The use of opioids for the treatment of chronic pain: a consensus statement from American Academy of Pain Medicine and American Pain Society 2008 [http://www.ampainsoc.org/advocacy/ opioids.htm]. 12-29-2008.

Pre-publication history

The pre-publication history for this paper can be accessed here: http://www.biomedcentral.com/1472-684X/9/14/prepub

doi: $10.1186 / 1472-684 X-9-14$

Cite this article as: Cepeda et al., Dose patterns in commercially insured subjects chronically exposed to opioids: a large cohort study in the United States BMC Palliative Care 2010, 9:14

\section{Submit your next manuscript to BioMed Central and take full advantage of:}

- Convenient online submission

- Thorough peer review

- No space constraints or color figure charges

- Immediate publication on acceptance

- Inclusion in PubMed, CAS, Scopus and Google Scholar

- Research which is freely available for redistribution
C Biomed Central 